\title{
RUINAS DE LA MODERNIDAD COMO TURISMO Y PATRIMONIO DE LA CONTRACULTURA URBANA.
}

\author{
Dr. Gerardo Vázquez Rodríguez \\ Doctor en Arte por la Universidad Autónoma de Barcelona. \\ Profesor-Investigador Universidad Autónoma de Nuevo León. \\ Facultad de Arquitectura.
}

\section{Resumen}

El panorama social del mundo a partir de la segunda mitad del siglo xx trajo consigo el rompimiento de paradigmas y creencias que se sustentaban bajo el proyecto de la modernidad y la revolución industrial. Europa fue la primera en evidenciar el decaimiento del proyecto moderno, la ruina aparece con la decadencia del modelo industrial y esto dará inicio a nuevos movimientos sociales que tratarán de adaptarse por medio de establecer una encontrada forma de ver e instrumentalizar la nueva realidad. Estos tiempos de cambio serian el escenario de la contracultura, esta pauta contracultural tiene como iconografía principal lo urbano e industrial en decadencia. Contemporáneamente el llamado turismo cultural ha subrayado la evidencia de la contracultura como huella de un acontecer histórico, principalmente en Europa aparecen cada vez más evidencias del fenómeno. El presente artículo intenta explorar los procesos bajos los que se da este acontecer de nuestros tiempos.

Palabras Claves: Turismo Cultural, Patrimonio, Contracultura, Modernidad, Contemporáneo, Ruinas. 


\title{
RUINS OF MODERNITY AS TOURISM AND HERITAGE OF URBAN COUNTERCULTURE.
}

\author{
Dr. Gerardo Vázquez Rodríguez \\ Doctor en Arte por la Universidad Autónoma de Barcelona. \\ Profesor-Investigador Universidad Autónoma de Nuevo León. \\ Facultad de Arquitectura.
}

\begin{abstract}
The social panorama of the world from the second half of the twentieth century brought with it the breaking of paradigms and beliefs that underpinned the project of modernity and the industrial revolution. Europe was the first to demonstrate the decay of the modern project, ruin appears with the decline of the industrial model and this will initiate new social movements that will try to adapt by establishing a found way to see and instrumentalize the new reality. These times of change would be the scenario of the counterculture, this countercultural pattern has as its main iconography the urban and industrial decline. At the same time, the so-called cultural tourism has emphasized the evidence of the counterculture as the mark of a historical event, especially in Europe, there is increasing evidence of the phenomenon. The present article tries to explore the low processes that this happening of our times gives.
\end{abstract}

Keywords: Cultural Tourism, Heritage, Counterculture, Modernity, Contemporary, Ruins 


\section{I.- A modo de introducción}

En las primeras décadas del siglo XXI se presenta un fenómeno de movilidad apostillado como "turismo cultural", el cual consiste en vincular el destino turístico con sus atractivos patrimoniales, incluyendo con mayor énfasis el rubro cultural como punto de atracción. Lo anterior deriva en una diferenciación - muy escueta- que determinan al "nuevo turismo" caracterizado por el aliciente cultural y se destaca por revalorizar el patrimonio histórico del lugar; en contrapartida se ubica el "viejo turismo", el cual es una expresión de la sociedad de masas y entre sus factores se enunciación se ubican los destinos semi artificiales y dotados de elementos recurrentes.

En el orden de esta breve disertación, el quid versará entorno al "turismo cultural", con mayor señalamiento en las expresiones contraculturales que se han acoplado a la dinámica turística. Es así que contemporáneamente entre las expresiones que desglosan un sentido para clarificar el concepto de "turismo cultural" se localiza la noción de "Heritage tourism" que se vincula a un propósito de resaltar el legado cultural e histórico del lugar o patrimonio de un sitio, más allá de los museos y los sitios de recreación la ciudad es acondicionada para ser recorrida con fines turísticos patrimoniales, donde se logra destacar una narrativa atractiva y seductora que crea la atmósfera de confidencialidad y apropiación de un lugar especifico.

Los elementos de identidad que prevalecen en el "turismo cultural" no sólo remiten a la apropiación del patrimonio histórico, así como de su relación artística pues además genera un acoplamiento de las narrativas de la cultura popular, de sus creaciones alejadas de la academia, de los movimientos sociales y sus propuestas estilísticas (y por lo tanto propuestas éticas). (Generalitat de Catalunya-ICMEC, 1996). Se atribuye así una relación con la cultura como un producto que manufacturan las entidades de la administración pública para el consumo del "turista cultural". Aunque posiblemente en este rasgo de producción de "mercancías culturales" no se limite a los actores gubernamentales sino es una dinámica que convoca a los propios ciudadanos para lograr anclar su lugar en el reconstruido mapa del turismo cultural.

\section{II.- Metodología}

Para aclara algunas cuestiones entorno a los términos cultura y contracultura se retomarán los elementos fundamentales que permiten una definición puntual. Así mismo, para tratar de evitar la incorporación de los minuciosos debates entorno a la cultura se considerará el uso del vocablo desde una simplificación pragmática que facilite su modo operativo. Si bien el concepto cultura se relaciona como noción cardinal de valores, reglas, 
percepciones, estilos, actitudes que el individuo expresa conforme sus peculiaridades y particularidades.

Entorno a ese juicio de la cultura como construcción de identidades se desprende su antítesis, es decir, si bien la cultura logra abarcar un espectro amplio del quehacer del individuo conforme a los distintos grupos sociales, bajo la línea de la dialéctica es posible argumentar la condición de un contrario, por lo tanto, si es concebida la idea de una cultura así mismo emana la noción de la contracultura. La cultura contiene un aspecto hegemónico, normativizado por reglas establecidas desde un grupo de poder, en consecuencia la idea de contracultura deriva en la contraposición de los elementos hegemónicos que rigen la cultura desde una concepción antagonista y contraria.

La contracultura es una expresión que -al igual que la cultura- genera propuestas de cohesión, rasgos de identidad, representaciones a través de signos y símbolos. Aunque si este criterio se dispone a un seguimiento a la línea posiblemente la contracultura sea un derivado de la cultura, que presenta y evidencia las contradicciones de la estructura social. La (contra)cultura se estratifica por medio de códigos, variaciones del lenguaje, cánones éticos y estéticos que conforman un proceso identitario a razón de cohesionar al grupo social. Por lo tanto, la cultura comprende, acopla, congrega las propuestas contraculturales a modo de someterla y depurarle las narrativas radicales, este acto de dominación puede ser en ocasiones un simple guiño seductor del poder, y en otras oportunidades bajo el recurso de la represión con el mismo objetivo de remover la consigna contra hegemónica y rehabilitarla al modo del discurso cultural homogéneo.

El turismo cultural se enmarca en una serie de estrategias de movilización, quizá hay ciudades que gocen de una cierta referencia indiscutible como punto de acción para el turista, cuestiones tales como ser la capital de una nación, por contar con atractivos turísticos que son regidos por ciertas temporadas, (por ejemplo en verano y destinos como playas y cruceros), algunas por sus recursos naturales (como montañas, bosques, entre otros), por sus vestigios y monumentos históricos; pero la tendencia emergente señala los puntos limítrofes de las megalópolis, no sólo en sentido del espacio físico sino de su proyección cultural mediante expresiones coyunturales que prevalecen como insignias del lugar.

La ciudad como ingrediente de lo cotidiano no es sino un elemento simbólico. La gran ciudad mitológica, divinizada e imbatible es ya un recuerdo, un afiche. "Toda ciudad está construida, hecha para nosotros un poco según la imagen del navío Argo, cada una de cuyas pieza no era una pieza original, pero que seguía siendo siempre el navío Argo, es decir, un conjunto de significaciones fácilmente legibles o identificables (Barthes, 2009: 349). 
Mediante la interacción de representaciones, imágenes, recuerdos, se descubren y describen "argumentos de identidad, hitos (objeto, hechos, personajes) que restablecen la memoria colectiva de las sociedades que las produjeron." (Vázquez y Soto, 2009: 19)

Esta discusión entorno al turismo y sus variaciones se esboza en una disertación que sirve, - para nuestros propósitos a modo de preámbulo,- para describir y categorizar la problemática desde la pluma del antropólogo Marc Augé en su obra "El viaje imposible", en el cual destaca:

(...) la forma de la ciudad con las formas de lo imaginario individual y colectivo y evocaré sucesivamente la ciudad-memoria (la ciudad en la que se sitúan tanto los rastros de la gran historia colectiva como los millares de historias individuales), la ciudadencuentro, a saber, la ciudad en la que hombres o mujeres pueden encontrarse o esperan encontrarse, pero también la ciudad que uno encuentra, que uno descubre y que uno aprende a conocer como a una persona; y por fin, la ciudad-ficción, la ciudad que amenaza con hacer desaparecer a las dos primeras, la ciudad planetaria que se asemeja a otras ciudades planetarias, la ciudad de imágenes y pantallas en las que la mirada se enloquece (...), o también aquella que trata de tomar forma, virtualidad, siempre inacabada en las periferias de la ciudad antigua. (Augé, 1998: 112)

Las sociedades de consumo han desterrado, en gran medida, la configuración de la ciudad moderna, se conservan vestigios, se acumulan estilos, se pasa por el sincretismo pero la esencia se diluye y el rescate del molde original parece una más de las formas identitarias que cubren la amalgama de discursos posmodernos sobre el cariz de la modernidad. La planeación urbana en estas nuevas "formas de hacer ciudad" gestiona la desacralización del patrimonio histórico para añadirlo a los elementos turísticos que eventualmente pueden motivar el arribo de más viajeros - de esta oleada del "nuevo turismo"- en busca de la experiencia, es por esto último que la administración de los espacios de la ciudad se diseñan entorno una narrativa de la "experiencia irrepetible".

El rasgo de la experiencia es un factor crucial para determinar el "turismo cultural", se vincula al aprendizaje, a la rememoración de la vivencia, sobre la historia no escrita en letras de oro, sobre las iniciativas más insólitas que han sido acalladas por un discurso hegemónico. El punto contradictorio se ubica en este mismo nudo de la narración, pues, aquello que se describe como único, como autentico que emana de propuestas reivindicativas, muchas de ellas con tintes contraculturales, se reconfiguraran para incorporarse a los atractivos turísticos y convertirse en una seña, en una marca particular de la región que será así mismo su publicidad. 


\section{III.- Resultados}

Si bien, bajo la lógica del "nuevo turismo" la cultura es una mercancía más que se ofrece al mercado, será posible que esto mismo suceda con la contracultura. Según algunos acercamientos al objeto de estudio las afirmaciones son indiscutibles. La cultura se torna como un elemento de valor de cambio, se tratan de incorporar viejas narrativas contraculturales debilitando su poder contestatario y adoptando su estilo como parte del inmobiliario de la ciudad. "El estilo en la subcultura viene, pues, cargado de significación. Sus transformaciones van «contra natura», interrumpiendo el proceso de «normalización». Como tales, son gestos, movimientos hacia un discurso que ofenda a la «mayoría silenciosa», que ponga en jaque el principio de unidad y cohesión, que contradiga el mito del consenso" (Hebdige, 2004: 34).

Para que se logre combinar de manera armónica el discurso y estilo contracultural al proyecto de la ciudad y sus atractivos turísticos se pulen ciertas aristas que históricamente han resultado incomodas e incompatibles con el poder hegemónico. Bajo ese traslape narrativo donde la contracultura se apoya en el mito, se vende como un afiche, se mercan los productos de la cultura como otra mercancía más en el sistema capitalista. Con el envoltorio de "contracultural" se dictan propagandas que más allá de su esencia contestataria se diluye en una lección educativa o en una historia recreativa enmarcada en el sumario turístico.

Este formato de "turismo cultural" muestra extremos perversos, donde un campo de guerra, de exterminio logra ser transformado en un parque temático, que incluye su inexorable souvenir, así también se dota de la simulación donde una región puede emular otras épocas y recobrar la experiencia de las formas de vida pasadas. Todo con fines más ligados a lo lucrativo que a lo educativo. Al parecer cuenta con un grupo social específico como nicho de mercado, este grupo es sino los jóvenes, que lejos de apropiarse de los ideales de los movimientos buscan la experiencia como modo de asimilación, es una experiencia controlada que cumple las expectativas de un tour, de un paseo turístico. "La evolución de la cultura juvenil debiera verse como una simple parte de este proceso de polarización. Específicamente, podemos citar el incremento relativo en el poder adquisitivo de la juventud de clase trabajadora, la creación de un mercado diseñado para absorber el excedente resultante." (Hebdige, 2004: 105) Para clasificar la noción de juventud se han ampliado los márgenes de los rangos de edad, pero la referencia es que al referir a la juventud en nuestros días la atención se dirige hacia la nueva generación denominada "millennials", la generación "Y", es la que consume estos productos de la nostalgia que sin duda el turismo cultural ha logrado colocar como parte de los productos de mayor prestigio. 
El supuesto del "turismo cultural" con vínculo contracultural descarga el alto voltaje simbólico que presentan ciertos espacios y movimientos sociales, utiliza a modo la sustancia radical que le da sentido a la expresión contestataria, pero con un nuevo matiz del código cultural que se traduce en un espacio apropiado para recreación. El turismo cultural ofrece el plus de la experiencia y la sensación de ser parte de un movimiento contracultural de resistencia.

Entre otros factores el "turismo contracultural" se ha apropiado de las ruinas de los movimientos, da un aire fresco a propuestas que en un principio circulaban fuera de la ley, lo convierte en símbolos, los revierte en referentes para el turista. Se valoriza el pasado desde una narrativa plana, sin antagonismo, como si fuera una situación que ha logrado llegar a un punto de equilibrio, la ciudad -por medio de sus administradores, políticos y la iniciativa privada- transforma el patrimonio cultural en una marca, es ahora un logo sublimado de la ciudad, recuperando espacios donde se vivieron batallas ideológicas para coronar la derrota de los contrarios. Este proceso de convertir toda la ciudad en una marca, de trocar su historia de luchas por el espacio político y simbólico para distorsionarlo al grado de mutarlo en un "parque temático" donde todos los habitantes resultan ser parte de la decoración.

Algunos espacios son apropiados por su fuerte carga histórica, por sus narrativas de ser una región que se disputa el derecho de ser diferente frente a la oleada de la globalización. El turismo contracultural contempla ese gesto de "autenticidad", aunque pueda ser un lugar cercano al "turismo de masas", lo promueve como contrario a los lugares de atracción de las ciudades globalizadas, esas ciudades que parecen ser calco y copia y que se reproducen en todo el planeta, pero, las vetas de la contracultura son también devoradas por una más de la cabeza de la hidra que se apropia de todo para convertirlo en mercancía. Lugares "sagrados" se desvirtúan de su función principal y se convierten en un "paseo dominical", la nostalgia es ahora un punto clave para ofrecer un mejor producto cultural al turismo.

La narrativa de este travesía de sedición se remonta a la década de los ochenta del siglo $\mathrm{XX}$; un mar de historias que se esconden en la inmensidad. Es el tiempo de las rupturas, de la escisión entre la utopía y los proyectos de nación. El tiempo de las decadencias se aproximaba, los grandes bloques económicos destinaban sus esfuerzos en una carrera armamentística que destellaba a una gran crisis. El bloque socialista ante sus inexorables virajes y golpes de mano, se dirige hacia el camino de la autodestrucción. El mundo mutilado resulta un archipiélago donde las grandes potencias buscan salvarse a pesar de los pesares. Así, el bando capitalista, de los países con mayores desarrollos de sus fuerzas productivas desenmascara sus propias contradicciones lo cual es la antesala de la recesión, el modelo se ha quebrado. Ante esas piezas sueltas se reconstruyen 
las identidades, sobre esas grietas se amalgama el sentido de una composición que resana los modos de vida entre la altivez de la nostalgia.

El sistema capitalista británico consiguió una bocanada de aire fresco a costa de depurar los privilegios de una clase media que habría de estancarse en la rutina, y desplazando a la clase trabajadora con medidas de corte económico que los arrojaban al despojo, sus condiciones de trabajo y de vida se asemejaban a las de un siglo atrás. De la mano de "La dama de hierro", los grandes sindicatos y las viejas reivindicaciones de la clase obrera británica se desplomaban, los gremios con mayor fuerza, envilecidos por la burocracia entregaban las trincheras para reconocer la victoria del modelo neoliberal.

La clase obrera quedaba a la deriva, cientos de familias fueron desterradas de sus viviendas, las zonas fabriles se convirtieron en ciudades fantasma, los mares donde había sido derribada "la armada invencible" ahora era la ruta de escape para los "desarrapados" que tanto velaba Engels con su prosa romántica. Otra salida fue hacia el interior; las familias tomaban las fábricas, no para volver a poner en marcha la producción sino para habitarlas, para formar un hogar, un refugio, una cueva para proteger de los nuevos depredadores neoliberales.

Se reaviva la tradición de ocupar viviendas abandonadas, viejos talleres, centro laborales cerrados por motivos de la guerra económica. Los viejos anaqueles donde se apilaban herramientas, son ocupados por utensilios de cocina; los extensos patios donde se embarcaban las mercancías se transforman en el área colectiva de juego de los infantes; las centenarias estructuras de la modernidad que recubren la gala de la industrialización son ahora una humilde vivienda de familias que sobreviven en la pesadilla del neoliberalismo.

En distintas partes del mundo y principalmente en toda Europa se presenta este movimiento social de la "ocupación" que denuncia la especulación inmobiliaria, la precarización del modo de vida, la ausencia de espacios dignos en la ciudad y el reclamo del derecho a la vivienda. Un elemento ha destacar entorno a la contracultura como acción emergente y respuesta a la coyuntura se da en el territorio británico donde se exponen matices de una ruptura con los símbolos locales.

Por otro lado, sin embargo, se basaba en una negación del lugar. Surgía en anónimos bloques de viviendas subvencionadas, en ignotas colas de parados, quintaesencia del barrio bajo. Era vacía, inexpresiva, desarraigada. En ello la subcultura punk se distingue de los estilos antillanos que fueron sus modelos básicos. Mientras que los jóvenes negros de ciudad podían catapultarse, mediante el reggae, hacia un inalcanzable e imaginario «más allá» (África, las Antillas), los punks vivían sujetos al tiempo presente. 
Estaban encadenados a una Gran Bretaña sin expectativas de futuro. (Hebdige, 2004: 93)

Esa extrañeza de un movimiento contracultural que adopta la ruptura como expresión,que desacraliza la simbología de la modernidad, que antes de negar a otros se niega a sí mismo, convierte su espacio y tiempo en una anti-utopía, el problema no es que como la «utopía» el lugar no exista, sino que su espacio es «ningún lugar». "Como el Dadá de André Breton, el punk parecía «abrir todas las puertas», pero esas puertas «daban a un corredor circular» (Breton, 1937). (Hebdige, 2004: 93) El movimiento contracultural del punk asimila la ocupación como una de sus dinámicas y acciones de identidad, la rebeldía de construir castillos de arena que se erigen sobre las ruinas de los viejos monumentos de gloria de la industrialización.

La ocupación de viejas fábricas, viviendas en los suburbios industriales es un movimiento motivado a partir del vocablo inglés de "squat". Esto en la relación con el castellano deviene en el término de "ocupación" el cual deriva en una transgresión ortográfica y economizado con el apócope de "okupa". El movimiento Okupa es una expresión de respuesta, de defensa y apropiación del espacio. La esencia de los "okupa" es un reflejo de la unión de fuerza en una lucha contra el avance de la maquinaria de destrucción capitalista, de la ruta marcada por sus cuatro ruedas: el despojo, la represión, el desprecio, la explotación; para el okupante el espacio es de quien lo habita.

El movimiento okupa es una resolución que dimana en una especie de exilio, un exilio dentro de las mismas ciudades, si bien las guerras y las dictaduras habrían de forzar la migración de los disidentes, esta nueva fase de la refriega del capital clausuraba las fronteras, pues, en un mundo globalizado las condiciones de miseria se habían homologado en gran parte del mundo. La respuesta estaba en la tierra, en las mismas coordenadas donde se habían sembrado las derrotas, donde se habrían de firmar los pactos para demoler la historia y construir un moderno centro comercial.

En 1961 la Internacional Situacionista pronunció una profecía sobre aquellos que construyen ruinas: después de los planificadores urbanísticos vendrán los últimos trogloditas de los suburbios y los guetos. Ellos sí sabrán construir (Marcus, 1993: 37).

\section{IV.- Conclusiones}

A modo de revisión de las ideas anteriores, la conexión entre las expresiones contraculturales y el turismo tensa su origen en un fundamento complejo, donde confluyen tanto la intención de preservar los espacios como una insignia de las luchas pasadas, mientras su otro rostro es la conversión en un tour de alta demanda turística, al quitar 
todo elemento contestatario existente. Es decir, el discurso de la contracultura es domesticado por las autoridades, se les reconoce como espacio de expresiones alternas a las hegemónicas, pero, se anexan a la dinámica del mercado, donde son tratados como una mercancía más que a la postre se convertirá en un souvenir para el turista.

Esta misma suerte lleva la corriente contracultural del punk, y en específico las acciones de la ocupación, es decir el movimiento okupa. Los okupas, que durante cerca de cuatro décadas, han brotado como una expresión de rebeldía contra las imposiciones de las autoridades para planificar las ciudades, y como denuncia ante la falta de oportunidades para obtener una vivienda digna. Vale recordar que si bien en el resurgir de los últimos años del movimiento okupa se vincula con mayor fuerza a tendencias de colectivizar los espacios y conformar puntos de referencia para la organización de los diferentes grupos que constituyen la pluralidad de tendencias políticas y sus demandas puntuales. Al parecer la apertura del movimiento okupa permitió que la multiplicidad de las demandas sociales formaran un discurso más incluyente y atractivo con lo cual se presentó un notable apoyo de la sociedad civil.

Pero, justo en esa misma condición de apertura e inclusión, la enunciación de las demandas fueron incorporadas a los esquemas de las plataformas políticas con fines electorales las cuales en su accionar tratan de acoplar las denuncias como si fueran partidarios del movimiento pero, por otro lado ejercen presión para que se cumplan la leyes y recrudecen las acciones represivas contra los renegados y transgresores del sistema.

El movimiento okupa al menos en Europa se caracteriza por contar con una fuerza de respaldo de los grupos autogestivos, ajenos a las instituciones, su fuerza es también una acumulación de vitalidad que dota la juventud. A pesar de contar con la tradición y reivindicar las luchas históricas, al parecer la narración que da significado al movimiento okupa es una mezcla que emana de la lógica de la globalización donde confluyen símbolos diversos, donde se enlazan resistencias diversas, se vuelve parte del paisaje común de las resistencia la iconografía de la rebeldía, donde jóvenes añaden a sus atavíos paliacates rojos en alusión a las luchas agrarias, diversas mercancía acompañadas por el culto al santo laico del "Che" Guevara, así entre la frontera de la mitificación y la reivindicación política los espacios de resistencia recomponen su identidad.

La paradoja deja de ser tal ante el hecho que el sistema no lucha frontalmente para derrocar a la expresiones contraculturales, sino que busca la manera de agenciar su desarrollo para dar la estocada final y apropiarse de su producción simbólica. "En un primer momento al sistema le basta con asimilar la resistencia mediante la apropiación de sus símbolos, la eliminación de su contenido «revolucionario» y la comercialización 
del producto resultante." (Heath y Potter, 2005: 46) No es que automáticamente vacíe el contenido del discurso contracultural sino que lo moldea de tal forma que lejos de volverse incomodo para el sistema es uno más de sus expresiones.

A manera de dar ejemplos que ilustren la contracultura en el turismo actual señalamos el ejemplo de La Kasa de la Muntanya en la ciudad de Barcelona, España, está construcción servía como un antiguo cuartel de la Guardia Civil que había sido edificado por la familia catalana Güell para dar seguridad al parque del mismo nombre y que fue diseñado por Antonio Gaudí. La institución armada abandona la edificación en 1983 y la propiedad pasó a manos del ministerio de interior y después al ministerio de hacienda, permaneció seis años sin que el Gobierno le diese uso hasta que en 1989 un grupo de activistas decidió okuparlo para acabar convirtiéndolo en un referente del movimiento antisistema barcelonés.

Desde Noviembre del 2016 el ayuntamiento de Barcelona promociona su ruta turísticahistórica "Iconos de Gràcia" en la que se destaca el edificio okupado de la "Kasa de la Muntanya" como icono del distrito y en la que figuran 18 puntos de interés para visitar en un recorrido entre la Sagrada Familia y el Parc Güell.(Guil J. 2016) Así un histórico templo del movimiento okupa barcelonés que pertenece al ministerio de hacienda y lleva tomado ilegalmente desde 1989 se convierte en iconografía del turismo contemporáneo.

Camden Town es reconocido en Londres como el barrio punk emblemático, este sitio emplazado al norte de la ciudad desde sus orígenes en el siglo XVII fue habitado por migrantes irlandeses, asiáticos y artistas; es distinguido por su famoso mercado Camden Town Market, lugar que alberga a cualquier cantidad de tribus urbanas de contracultura. Los inicios del mercadillo son alrededor de 1974, cuando unos hippies de la zona comenzaron a montar puestos en los que vendían su artesanía y ropa usada; los hippies londinenses fueron precursores de las primeras ocupaciones de ruinas de la modernidad temprana y espacios en desuso dentro de esta capital, en mucho el movimiento de ocupación punk de Londres fue una replica de las primeras comunas hippies de la ciudad.

El impacto de este mercado de contracultura es tan grande que cada fin de semana alberga más de 100.000 personas y representa una icono turístico promocionado por paginas oficiales de la capital británica, durante el día la zona está saturada de turistas y es una visita obligada, pero durante la noche se convierte en una zona poco recomendada para el público en general. ( Londres.es-Camden Town 2016)

Tras la caída del Muro de Berlín la Casa Okupa Tacheles ubicada en un edificio en ruinas del este de Berlín, fue el centro cultural alternativo más famoso de esta ciudad Germana, 
desde finales de los años ochentas hasta entrada la primera década del siglo XXI ésta ocupación antisistema se erigió como un icono de contracultura. Muchos artistas ocuparon los edificios que habían quedado vacíos debido a la migración del este hacia el oeste y los ciudadanos creyeron que era una buena idea que alguien diera un uso a los edificios en vez de dejarlos derrumbarse. Tacheles se volvió un lugar emblemáticos de Berlín y su visita turística era imprescindibles hasta su reciente cierre. Actualmente este edificio esta transformado en un hotel que trata de recrear la atmosfera de contracultura impuesta por su uso común durante más de treinta años (disfrutaberlin.com 2016).

El barrio Okupa danés Christianshavn se encuentra en la Ciudad de Copenhague, Dinamarca, de origen era un antiguo sector militar pero en 1971 el ejército abandonó el cuartel y los okupas lo eligieron como lugar donde instalarse y hacer de esas veintidós hectáreas un espacio alternativo donde desarrollar una forma de vida diferente y contrario a la cultura del resto de la ciudad. La adecuación del antiguo centro militar al barrio libertario partió de una premisa básica: la creatividad. De este modo crearon talleres, tiendas, escuelas y guarderías, negocios colectivos, programas de reciclaje, anticuarios, locales para conciertos, grupos de teatro y un sinfín de espacios más basados todos en sus premisas de amor y paz. Actualmente este barrio es un lugar de vivienda okupa y residencial donde se suscitan gran cantidad de turistas que lejos de buscar un sitio espectacular esperan encontrar vestigios del significado y del simbolismo que esta barrio tuvo para la historia del país. El gobierno danés estuvo de acuerdo con esta comunidad aunque dio sólo tres años para lo que los políticos consideraron una experiencia social a corto plazo. Cuando finalizo este plazo comenzaron los enfrentamientos entre el gobierno y los okupas produciéndose durante décadas juicios, presiones, manifestaciones y números actos en contra llegándose incluso a ocupar la radio danesa en 1973. Tanto los medios impresos y digitales están repletos de informaciones que ilustran la larga historia de este sueño ocupa cargado de momentos de esplendor y de oscuridad (visitdenmark.es).

Situado en el norte de la Ciudad de México se encuentra el Museo Universitario del Chopo, propiedad de la UNAM, monumental edificio Art Noveau que fue construido hace más de 100 años en Alemania y trasladado a México en 1903, inicialmente funciono como Museo de Historia Natural pero el antiguo edificio a partir de 1975 se convierte en un incansable centro promotor y difusor de la cultura universitaria y de las más variadas expresiones del arte actual en todas su manifestaciones, en Octubre de 1980 se crea alrededor del Museo del Chopo, el "Tianguis del Chopo" mercadillo de contracultura que inicialmente se instalaría solo por un mes pero que debido a la cantidad de personas que logra reunir todos los sábados se ha consolidado a lo largo de los años como un punto icónico de la cultura antisistema, abundantes tribus urbanas coexisten en este lugar intercambiando y mercadeando libros, música, arte, ropa y cultura 
en general. Es común encontrar tanto al Museo como al Tianguis del Chopo en páginas que los denotan como punto turístico para personas interesadas en encontrar los vestigios más sobresalientes de la contracultura mexicana. (https://www.maspormas.com/2016/03/02/tianguis-del-chopo/)

\section{Referencias bibliográficas}

Augé, M. (1998) El viaje imposible. El turismo y sus imágenes. Barcelona, Editorial Gedisa.

Barthes, R. (2009) La aventura semiológica. Barcelona; Paidós.

Camden Town. Londres. Es : https://www.londres.es/camden-town

Generalitat de Catalunya-Institut Català de la Mediterrània d'Estudis i Cooperació (1996). Fòrum civil Euromed (1995: Barcelona). Cap a un nou escenari d'associació. Barcelona.

Guil, J. (21 de Noviembre de 2016). Colau incluye una casa okupa en una guía turística de Barcelona. ABC Cataluña.Recuperado de http://www.abc.es/ espana/catalunya/politica/abci-colau-incluye-casa-okupa-guia-turisticabarcelona-201611210748_noticia.html

Heath, J. y Potter, A. (2005) Rebelarse vende. El negocio de la contracultura. Bógota, Editorial Taurus.

Hebdige, D. (2004) Subcultura. El significado del estilo. Barcelona, Paidós

Marcus, Greil. (1993) Rastros de Carmín. Una historia secreta del siglo XX. Barcelona : Editorial Anagrama

Tianguis del Chopo: https://www.maspormas.com/2016/03/02/tianguis-del-chopo/

Tacheles Berlín https://www.disfrutaberlin.com/tacheles

Vázquez R, G. y Soto C, K. (2009) Hacia una aproximación del imaginario de la ciudad de Monterrey en el albor del siglo XXI. En Narváez, B. (Ed.) AEDIFICARE 2009, (págs. 17 34). Monterrey; UANL.

Visitdenmark.es http://www.visitdenmark.es/es/copenhague/atracciones/christiania 